\title{
BMJ Open Risk of infection and contribution to transmission of SARS-CoV-2 in school staff: a systematic review
}

\author{
Sudip Jung Karki (iD , ${ }^{1}$ Alexandar Joachim, ${ }^{2}$ Torben Heinsohn (D) ,1,3 Berit Lange ${ }^{1,3}$
}

To cite: Karki SJ, Joachim A, Heinsohn T, et al. Risk of infection and contribution to transmission of SARSCoV-2 in school staff: a systematic review. BMJ Open 2021;11:e052690. doi:10.1136/ bmjopen-2021-052690

- Prepublication history and additional supplemental material for this paper are available online. To view these files, please visit the journal online (http://dx.doi.org/10.1136/ bmjopen-2021-052690).

SJK and AJ are joint first authors.

Received 22 April 2021 Accepted 08 0ctober 2021

Check for updates

(C) Author(s) (or their employer(s)) 2021. Re-use permitted under CC BY-NC. No commercial re-use. See rights and permissions. Published by BMJ.

${ }^{1}$ Department of Epidemiology, Helmholtz Centre for Infection Research, Braunschweig, Germany

${ }^{2}$ Department of Paediatrics,

Faculty of Medicine and University Hospital, University of Cologne, Cologne, Germany

${ }^{3}$ German Center for Infection

Research (DZIF), Braunschweig, Germany

Correspondence to

Sudip Jung Karki;

SudipJung.Karki@helmholtzhzi.de

\section{ABSTRACT}

Objective To summarise the comparative risk of infection in school staff and their contribution to SARS-CoV-2 transmission.

Design Systematic review using Preferred Reporting Items for Systematic Reviews and Meta-Analyses guideline.

Data sources MEDLINE, WHO COVID-19 database and preView were searched on 29 January 2021.

Eligibility criteria We included studies that reported risk of SARS-CoV-2 infection in school staff or transmission of SARS-CoV-2 in school settings.

Data extraction and synthesis Data extraction was done in duplicates. Data synthesis was qualitative. We report attack rates and infection risk in school settings for staff and students stratified by control measures taken and infection dynamics at the point of data collection.

Results Eighteen studies were included. Three studies in low incidence settings showed low attack rates similar for teachers and students. Five studies in medium incidence settings and two studies in high incidence settings showed secondary attack rates up to $16 \%$ in school staff.

Seroprevalence studies, two in each low and high incidence settings showed an infection risk of $0 \%-0.2 \%$ and $1.7 \%-28 \%$ for teachers.

The risk of infection for teachers compared with students were similar in one study in low incidence setting, higher in three studies (RR 1.2-4.4) and lower in three studies in medium to high incidence settings. The risk of infection for teachers in a high infection environment is higher in face-to-face than in distance classes when compared with general population groups. The risk of infections as well as risk of hospitalisation both increased for teachers during school openings compared with school closure.

Conclusion While in low incidence settings there is little evidence for school staff to be at high risk of SARS-CoV-2 infection, in high incidence settings there is an increased risk of SARS-CoV-2 infection in school staff teaching faceto-face compared to staff teaching digitally and general population.

PROSPERO registration number CRD42021239225.

\section{INTRODUCTION}

COVID-19 is a global public health threat, caused by SARS-CoV-2. ${ }^{1}$ Although people of all ages are affected, the severity of the clinical course increases with age (more severe in people $>65$ years of age).$^{2}{ }^{3}$ Children and
STRENGTHS AND LIMITATIONS OF THIS STUDY

$\Rightarrow$ The study results were stratified according to the prevalence of infection during data collection period and prevailing control measures in the school setting at that time.

$\Rightarrow$ The infection risk in teachers/school staff were compared with infection risk in students, general population and teachers.

$\Rightarrow$ The results from included studies were heterogeneous.

adolescents most commonly experience a mild clinical course and show less severe outcomes compared with adults and ageing people. ${ }^{4-7}$ When showing severe outcomes, long-term complications can be equal or worse in children than in adults. ${ }^{8}$

Non-pharmaceutical interventions (NPIs) like isolation, quarantine and social distancing including large-scale school closures are applied near-universally to curb the transmission of SARS-CoV-2. ${ }^{9}$ 10 Such conventional public health measures appear to reduce the number of new infections. ${ }^{11}$ However, school closures alone are not sufficient to prevent community transmission of SARS-CoV-2. ${ }^{12} 13$

Several systematic reviews, meta-analyses and large ecological analyses have focused on effects and adverse effects of school closures mainly assessing endpoints concerning the effect on community transmission as well as effects on children. ${ }^{9}{ }^{14} 15$ Long-term school closures are a threat to the physical and mental health of children and adolescents and intensify the racial and socioeconomic gaps in society. ${ }^{16-20}$

Nevertheless, keeping schools open when community transmissions are increasing may be posing a threat to school staff in particular, as their age leaves them more at risk of severe infections compared with students. Evaluating the risk to school staff as well their role in schools and community transmission is thus essential to an evidence-based approach to pandemic public health strategies. 
In an umbrella review (Lange et al, submitted) we did not find any systematic review focusing on risk of and contribution to transmission of school staff.

The risk of infection in school staff in dynamic infection environments depends on the population infection dynamic as well as the infection dynamic within schools, the susceptibility of staff to the infection and the number of contacts of the staff at that time. An absolute estimate of the risk of infection is futile due to its dependence on the evolving context. We have therefore collated the existing evidence on the relative risk of infection compared with other population groups in original papers and existing reports and stratified by infection dynamic prevalent during the period of data collection.

\section{METHODS}

\section{Protocol and registration}

We followed Preferred Reporting Items for Systematic Reviews and Meta-Analyses (PRISMA) guidelines ${ }^{21}$ and registered this review with PROSPERO.

\section{Search strategy}

We searched MEDLINE and preView most recently on 29 January 2021 by using search terms "SARS-CoV2" /"COVID-19" and "teacher"/"school" combinations with OR and AND Boolean operators. We also searched WHO COVID-19 database for relevant literatures.

We did not restrict our search to any study design or language of publication. Preprints are included in this search if available from preprint databases. We did not consider the preprint available only on homepages or institute websites.

\section{Eligibility criteria}

Studies reporting the risk of COVID-19 in teachers or any school staff or any kind of involvement of teacher or school staff in SARS-CoV-2 transmission were eligible for inclusion in the review. Articles published in peer-reviewed journals, preprints, technical reports and case reports were included. Studies and reports were also included based on expert suggestion.

Modelling studies, opinion analysis, media reports, reviews and meta-analysis were excluded. We also excluded studies reporting SARS-CoV-2 transmission in students and school staff but in different school settings and studies reporting solely risk factors for SARS-CoV-2 infection in teachers or students. The Patients/Population, Intervention, Comparison and Outcomes for the included studies is presented in table 1 .

\section{Study selection}

Two reviewers (SJK and AJ) screened the title and abstracts and read the full-text independently based on the predefined eligibility criteria. Inconsistencies and disagreements in the judgement were resolved by consultation with a third reviewer (BL).

\section{Patient and public involvement}

Patients or the public were not involved in any stage of this systematic review.

\section{Data extraction}

Two reviewers (SJK and AJ) independently extracted the data from included studies into a prespecified form. Disagreements in the data extraction process were resolved by consultation with the third reviewer (BL). Data related to study characteristics (source, name of first author, study design/ type, date of data collection), study population (population of staff, population of students and population of contacts), main issue, study setting, comparator, attack rate in staff, attack rate in student, infection risk in student, infection risk in staff, outcome and results were extracted.

\section{Quality appraisal}

The Agency for Healthcare Research and Quality checklist was adapted to assess the quality of included studies. ${ }^{22-24}$

The risk of bias domains used were selection bias, performance bias, attrition bias, detection bias, reporting bias and information bias. The overall risk of bias for included studies was classified as high, unclear, medium or low risk of bias. The criteria for high risk of bias for included studies are high risk of bias in any one of the domains. Studies with unclear risk of bias in any one of the key domains and no high risk of bias in any other domain were deemed unclear risk of bias. Studies with medium risk of bias in any one of the domains and low risk of bias in all other domains were deemed medium risk of bias and those with low risk of bias in all the domains were deemed low risk of bias.

\section{Synthesis of results}

Qualitative data synthesis was performed by describing study characteristics and main research questions, with the main conclusions of included studies presented narratively and in table format. The findings were presented based on the different type of SARS-CoV-2 transmission found in the school setting. When absolute numbers were available, we calculated (secondary) attack rates. When authors already calculated the attack rate we report them as given. Where infections risk is given by either seroprevalence or PCR-based

Table 1 Patients/Population, Intervention, comparison and Outcome for included studies

\begin{tabular}{lllll}
\hline & Patients/Population & Intervention/Exposure & Comparator & Outcome \\
\hline $\begin{array}{l}\text { Transmission of SARS- } \\
\text { CoV-2 in school }\end{array}$ & $\begin{array}{l}\text { School staff, any contacts of School, primary school, } \\
\text { school staff }\end{array}$ & secondary school & $\begin{array}{l}\text { School children, general } \\
\text { population, present in the } \\
\text { school (distance learning), } \\
\text { school staff in different school } \\
\text { forms or learning situations }\end{array}$ & $\begin{array}{l}\text { Secondary attack rates as } \\
\text { reported by authors of original } \\
\text { papers, relative/infection risk, OR }\end{array}$ \\
& & & S
\end{tabular}




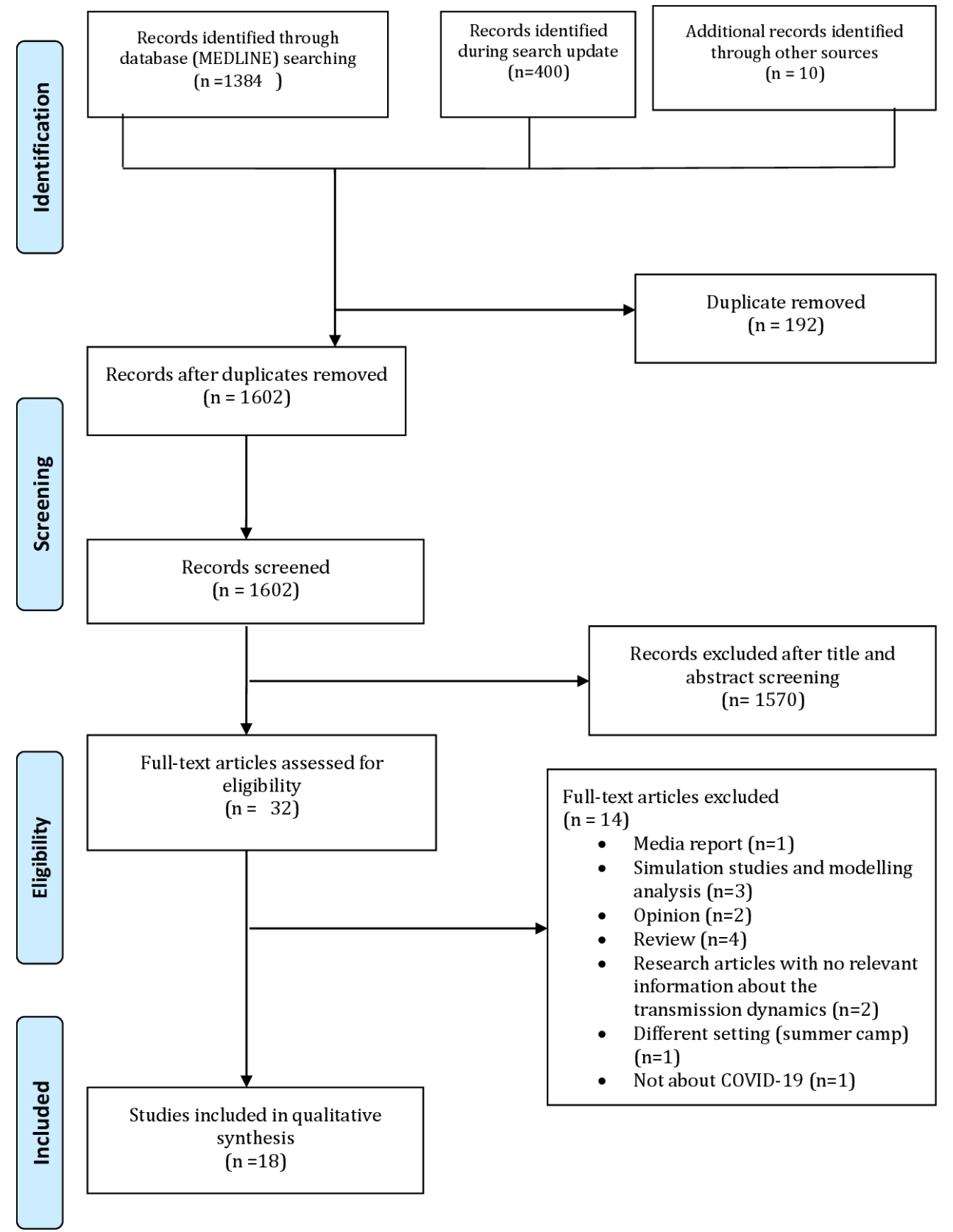

Figure 1 Preferred Reporting Items for Systematic Reviews and Meta-Analyses flow diagram.

testing, we report them as given. All outcomes are reported stratified by infection environment and NPIs measures in place during data collection periods.

\section{RESULTS}

\section{Study selection and study characteristics}

The search yielded 1784 studies. Of these, eight met the inclusion criteria. A further 10 studies were found through screening references of systematic reviews, meta-analyses and following expert suggestions. Eighteen studies were included in the review; the selection process is described in figure 1 .

Almost all of the included studies were conducted in 2020. Ten of the included studies had a data collection/ analysis period from January to June. ${ }^{25-34}$ Three studies have collected data from April to July, ${ }^{35}$ in June/July ${ }^{36}$ or in July only. ${ }^{37}$ One study collected data from July to September ${ }^{38}$ and two studies had data collection periods from August to November. ${ }^{39} 40$ One study uses data from March 2020 to January $2021,{ }^{41}$ and the remaining study analysed data from 12 March 2020. ${ }^{42}$ During the data collection period, the total number of SARS-CoV-2 cases in the countries of study ranged from 1.44 cases/million to 26802 cases/million and SARSCoV-2-related deaths from 0.03 deaths/million to 339.68 deaths/million. ${ }^{43}$ Similarly, the number of new cases per day at the start of the study interval ranges from 0 to 169.71 cases per million per day. At the end of the study period the incidence ranges from 0.29 to 423.22 cases per million per day. ${ }^{43}$ 
The studies were originated in Australia, ${ }^{3035} 38$ France, ${ }^{27} 28$ Germany, ${ }^{25}$ Ireland, ${ }^{42}$ Israel,${ }^{32}$ Italy,${ }^{40}$ Panama,${ }^{29}$ Singapore,${ }^{34}$ Sweden, ${ }^{313}$ the UK, ${ }^{36}$ Scotland ${ }^{41}$ and the USA. ${ }^{263739}$ Among them three were reports published by the Public Health Agency of Sweden ${ }^{31}$ and by the National Centre for Immunization Research and Surveillance, New South Wales, Australia. ${ }^{3538}$ Five were published in preprint ${ }^{252833} 3741$ with the remaining ten studies published in peer-review journals.

All included studies provide information about either risk of SARS-CoV-2 infection in teachers and/or students, transmission of SARS-CoV-2 in school settings or seroprevalence of SARS-CoV-2 IgG antibodies in school staff or school settings. Most of the included studies report attack rates, ${ }^{27} 2930$ 32 34-36 38-40 42 seroprevalence of SARS-CoV-2 $\mathrm{IgG}^{25} 262837$ or infection risk ${ }^{31} 3341$ among teachers and students. The characteristics of included studies are tabularised in table 2.

\section{Quality assessment}

Among the included studies, six have a low risk of bias, ten studies have a medium risk of bias, one has an unclear risk of and one has a high risk of bias. Reasons for assigning medium risk of bias were: not all contacts were tested in contact tracing studies and some of the studies used only case notification data from nationwide surveillance database. This increases the possibility of missing asymptomatic cases and cases that were not reported. The reason for assigning unclear risk of bias was that the occupation code was missing for $25 \%$ of the confirmed cases. It was unclear how the study group dealt with this issue. The reason for assigning high risk of bias to one of the studies was selective reporting of results, low participation rate and use of questionnaires to assess symptoms. This increases the possibility of recall and misclassification bias. The overall risk of bias assessments for included studies are tabularised (online supplemental table $1)$.

\section{Findings}

Attack rates in school staff and students

Eleven studies reported data on attack rates in schools. ${ }^{27} 293032$ 34-36 38-40 42 The detailed information is provided in online supplemental table 2.

Four studies found no secondary transmission in schools following index cases. ${ }^{27} 343542$ Of the remaining seven studies, six reported attack rates of 0\%-13\% following outbreaks among students and attack rates of $0 \%-16.6 \%$ following outbreaks among school staff. ${ }^{29}{ }^{30} 32$ 38-40 One of the studies reports 100 secondary cases in staff and 22 in students related to one outbreak. ${ }^{36}$

Secondary attack rates among pupils were $0.14 \%,{ }^{39}$ $0.3 \%,^{30} 0.81 \%{ }^{38}$ and $3.8 \% .^{40}$ The latter study further differentiated between $6.6 \%$ in secondary schools and $0.38 \%$ in primary schools with no secondary transmission in preschools. ${ }^{40}$ The secondary attack rate of pupils to staff was $1 \%$ in one study. ${ }^{30}$

Regarding transmission among school staff, values of $1.29 \%,{ }^{38} 3.5 \%^{29}$ and $4.4 \%{ }^{30}$ and $16.6 \%{ }^{32}$ were reported. Two studies showed no transmission among staff. ${ }^{39} 40$
Risk of infection in seroprevalence studies

Four studies ${ }^{25} 262837$ describe the detection of antibodies in school contexts in Germany, France and the USA. The detail information is provided in online supplemental table 3 .

In Germany, analysis of 13 schools in Saxony showed past infection in $0.2 \%$ of teaching staff and $0.7 \%$ of students, with an average of $0.6 \% .{ }^{25}$ In comparison, seroprevalence in northern France was $25.9 \%$ on average, with $28.75 \%$ in teaching staff and $12.8 \%$ in students. ${ }^{28}$ In the USA, 14 days after a school index case, $1.66 \%$ of students and $0 \%$ of teachers tested positive for antibodies. ${ }^{26}$ In the Midwest of the USA, $1.7 \%$ of teaching staff had a history of infection. ${ }^{37}$

\section{Stratification of studies according to risk of infection after index case during data collection period}

In order to better classify these heterogeneous results, study results were differentiated by two aspects: first, into three categories according to the prevalence of infection at the time of data collection and second, according to the prevailing measures in schools at that time (table 3). The detailed information about stratification of studies according to infection dynamics and NPIs during data collection period is provided in online supplemental table 4.

Three studies conducted while the incidence of infection was low found no secondary cases following index cases. ${ }^{2735}{ }^{42}$ Five studies conducted while the incidence of infection was in the medium range, reported that $0 \%-4.4 \%$ of school staff and $0 \%-6.5 \%$ of students developed secondary infections following index cases. ${ }^{29} 30363840$ Two studies conducted while population infection incidence was reported that up to $16 \%$ of school staff developed infections following index cases, and up to $13 \%$ of students. ${ }^{32} 39$

Regarding seroprevalence studies, two studies conducted during a medium incidence of infection show an infection risk of $0 \%$ and $0.2 \%$ for teachers ${ }^{25}{ }^{26}$ whereas two studies conducted during a higher incidence of infection showed a seroprevalence of $1.7 \%$ and $28 \% .{ }^{2837}$

\section{Comparison of the risk of infection of teachers and other population groups}

Two studies ${ }^{31} 33$ describe the risk of infection in Sweden. Here, during a period of high infection incidence, secondary schools were closed and pupils were taught in distance, while primary schools remained open and faceto-face teaching continued. The relative risk (RR) and 95\% CI for teachers in open primary schools was 1.1 (0.9 to 1.3), whereas RR and $95 \%$ CI for teachers in closed schools was 0.7 (0.5 to 1$){ }^{31}$

The chance for primary school teachers to become infected with SARS-CoV-2 was about twice as high as that of secondary school teachers in distance, with the OR and 95\% CI of 2.01 (1.52 to 2.67). Partners of primary school teachers and parents of primary school students also had an increased chance of becoming infected, OR 1.3 (1 to 1.68) and OR 1.15 (1.03 to 1.27), when compared with secondary 


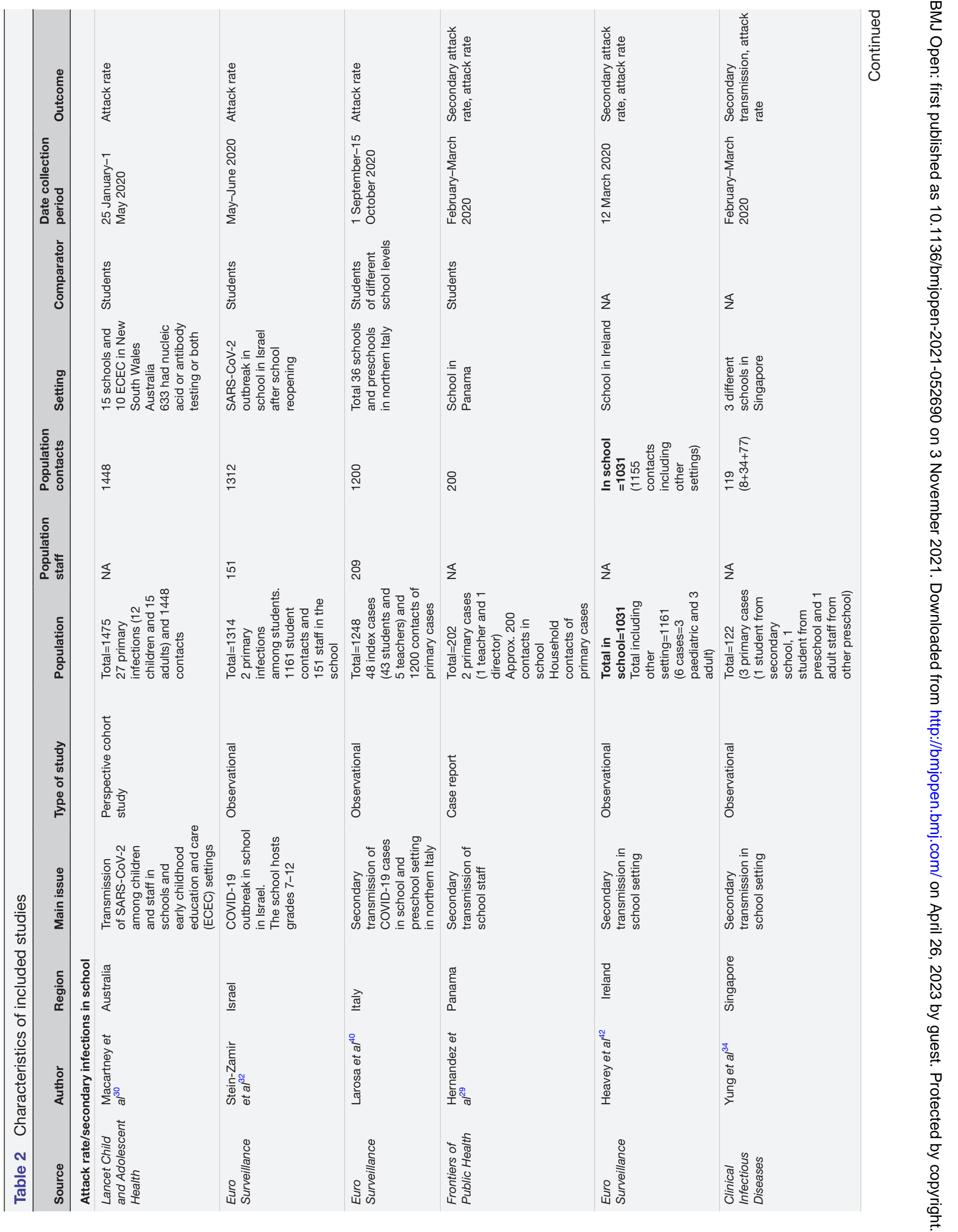




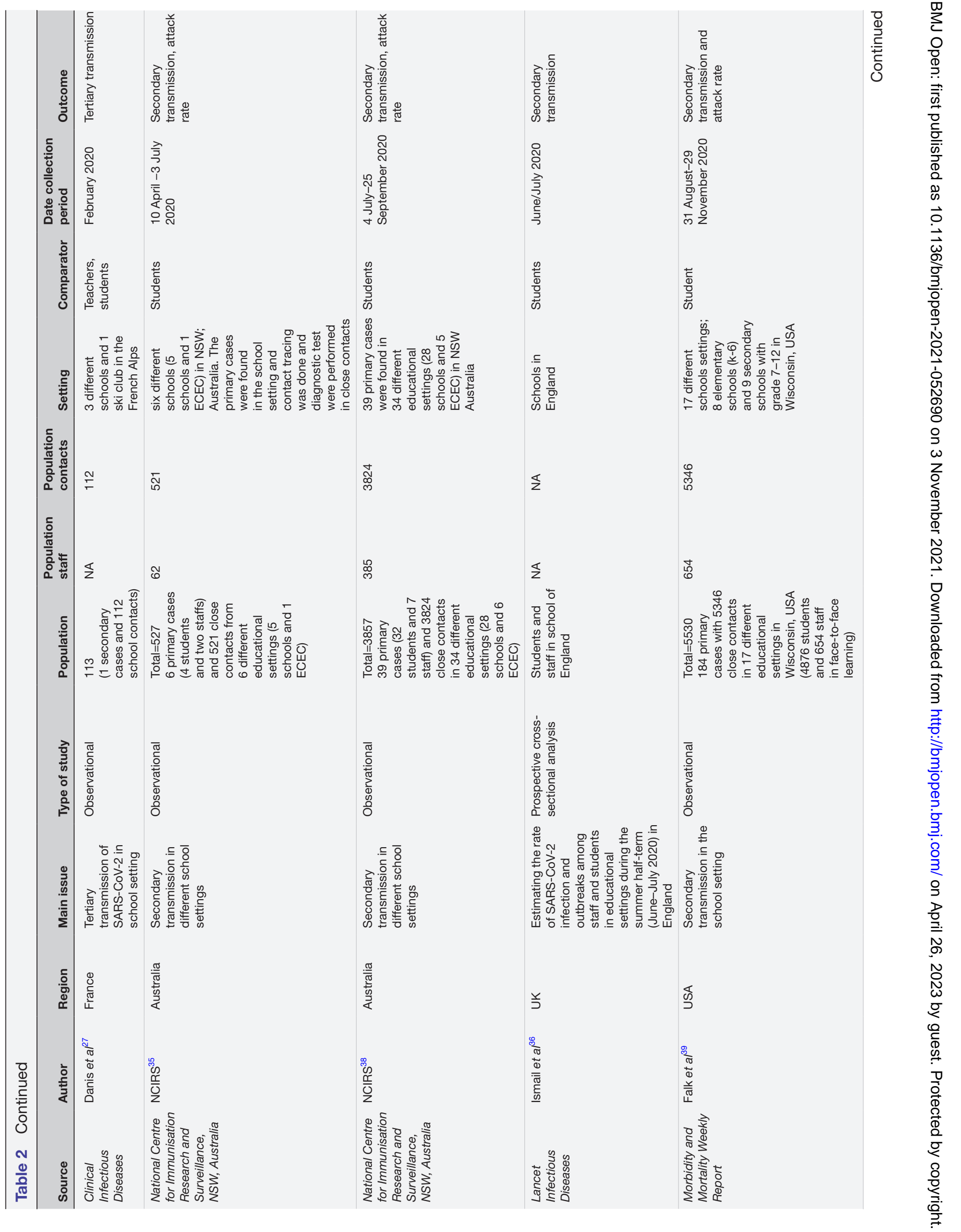




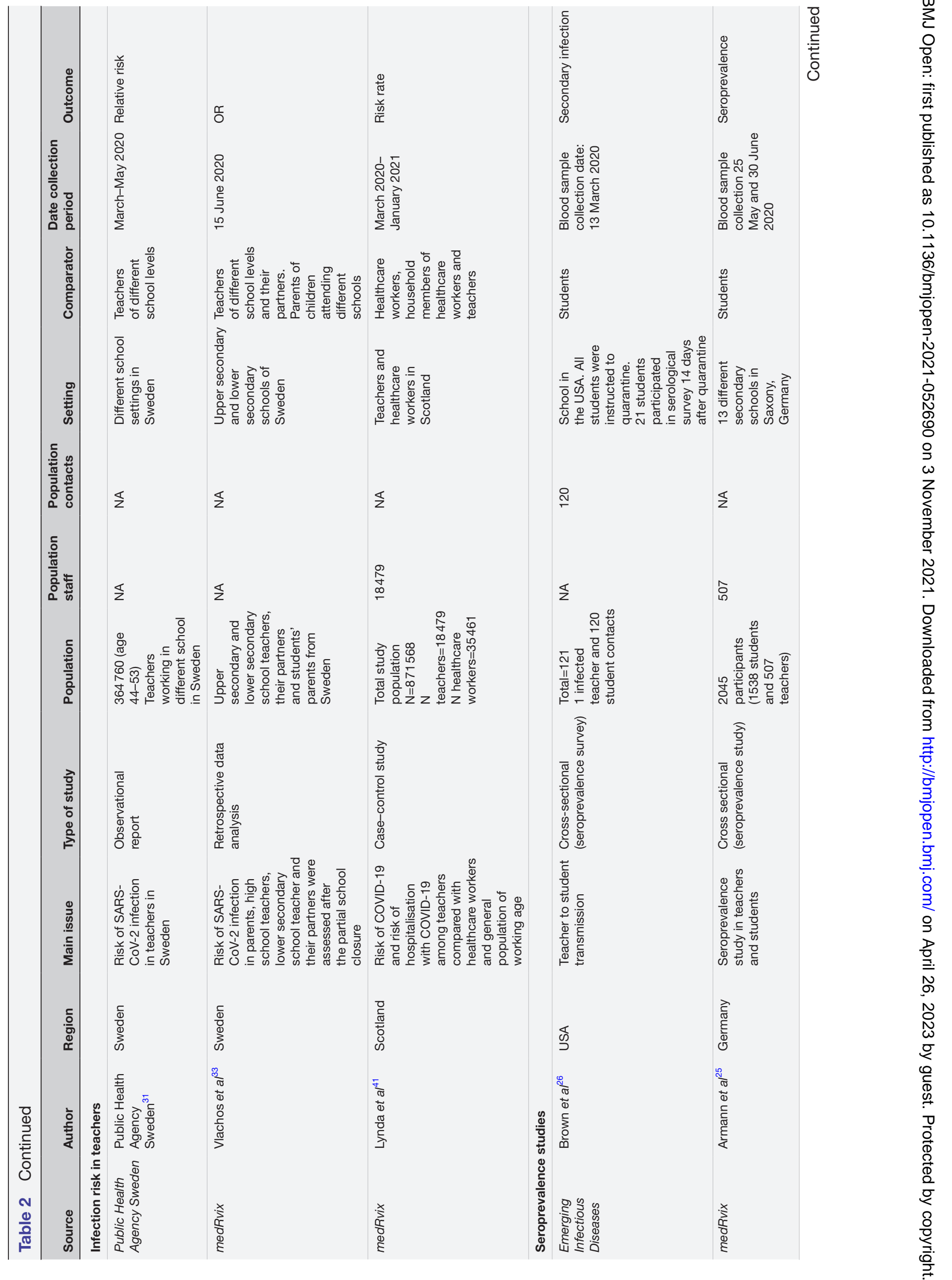




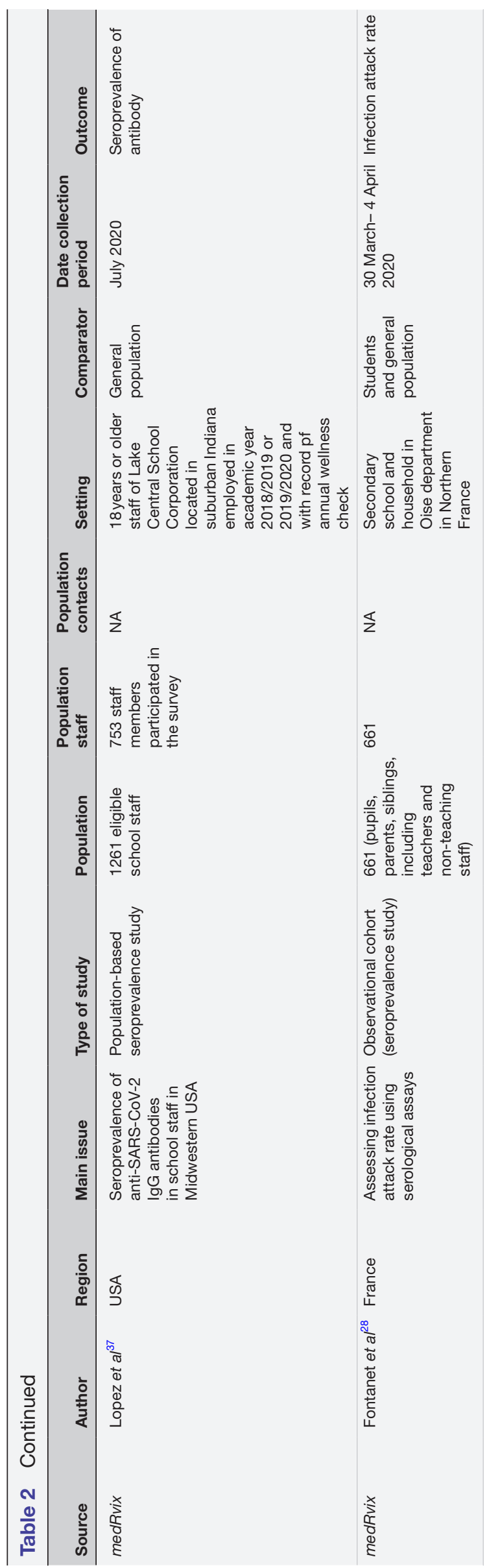

schools cohorts. ${ }^{33}$ The comparison of infection risks and attack rates of school staff with other population groups is presented in table 4 .

A study from Scotland compares the risk of infection as well as the risk of hospitalisation of teachers during a period of high infection incidence with school closures and a period of lower infection incidence and open schools with both hospital staff and the general population. The risk of infection as well as the risk of hospitalisation of teachers during school closures is about half that of the general population (RR 0.5). Following school openings, the risk of infection increased threefold and is higher than that of the general population (RR 1.42) and the risk of hospitalisation doubles and is similar to that of the general population (RR 0.97). ${ }^{41}$

\section{DISCUSSION}

On stratification of heterogeneous results in this review of infection risk and secondary attack rates of SARS-CoV-2 infection in school staff, we show that during a low incidence of infection at the time of data collection, attack rates are rather low and similar among teachers and students compared with medium and high incidence of infection. During a medium incidence and mortality rate of SARS-CoV-2 at the time of data collection, secondary attack rates in school were higher and higher for teachers than among students $(0 \%-6.6 \%)$. In settings with high infection dynamics during data collection (incidence $>25 / 7$ days $/ 100000$, deaths per day $>5 /$ million population) intervals, the risk of infection following outbreaks in schools is usually higher among teachers than among students (up to $16 \%$ ), ${ }^{32}$ and the risk of infection via seroprevalence studies is up to $28 \% .^{28}$

Infectious students tend to infect other students rather than teachers. The student to staff transmission rate is low, that is, $0 \%$, compared with staff to student transmission, which was $1 \%$ in the same setting. ${ }^{30}$ This is in line with several studies suggesting low secondary transmission from students to teachers in different countries. ${ }^{126}$ Infectious teachers tend to infect other teachers rather than students. ${ }^{32} 36$ This is supported by a study from Australia $^{44}$ and other transmission studies. ${ }^{29} 3045$ The study summarises that in the school setting the transmission risk is higher among adults and infectious children are less likely to infect teachers. ${ }^{44}$

In setting with high population infection incidence during data collection, the risk of infection was higher among teachers in face-to-face classes compared with teachers in distance classes (RR 1.1-2.0 risk of infection) ${ }^{31}$ and the risk of infection as well as the risk of hospitalisation increased among teachers during school openings compared with school closings (one study, RR=3 for infection risk and one study, $\mathrm{RR}=2$, for hospitalisation risk) ${ }^{41}$

Compared with the general population, the risk of infection and hospitalisation was lower for teachers during school closures than for the general population $(\mathrm{RR}=0.5$ in one study) and increased $(\mathrm{RR}=1.42)$ after 


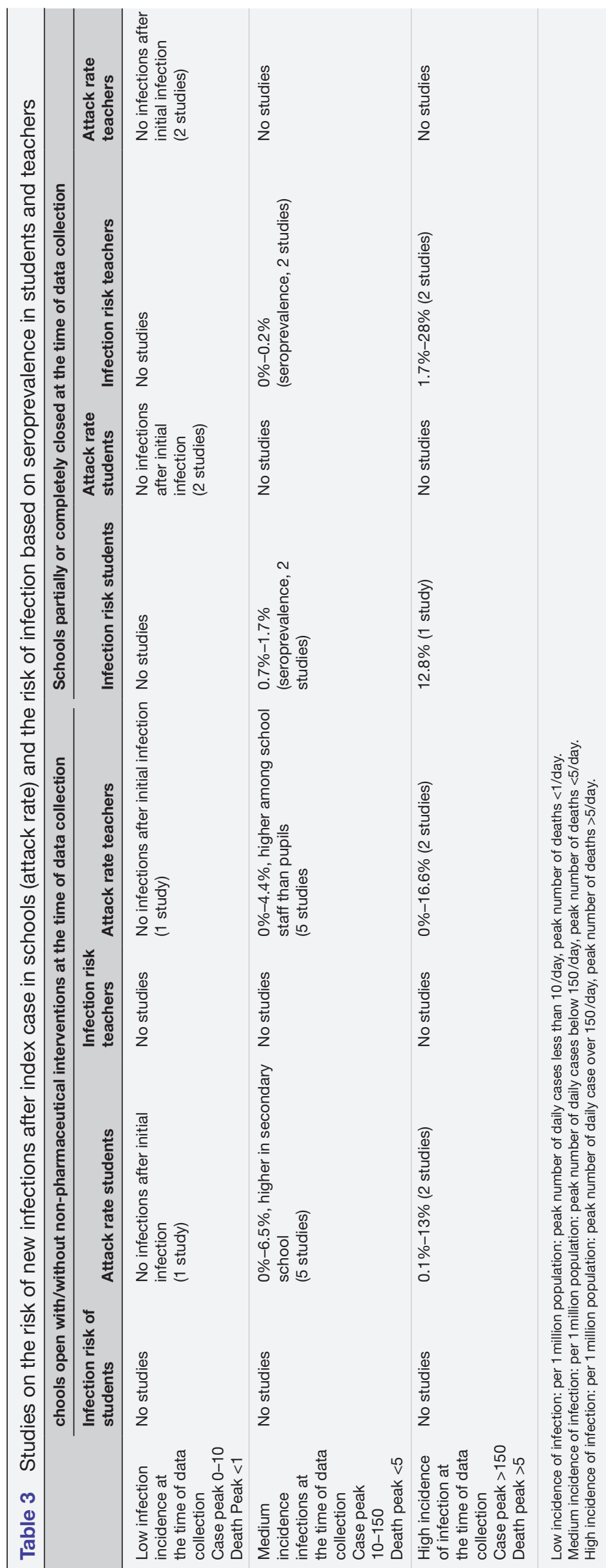

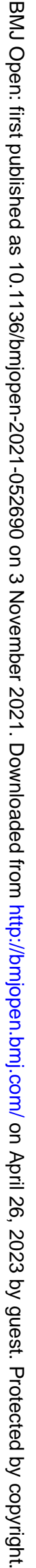


Table 4 Comparison of infection risks and attack rates of school staff with other population groups

\begin{tabular}{|c|c|c|c|c|c|c|}
\hline \multirow[b]{2}{*}{$\begin{array}{l}\text { Infection } \\
\text { dynamics }\end{array}$} & \multicolumn{3}{|c|}{ Schools open with/without non-pharmaceutical interventions } & \multicolumn{3}{|c|}{ School (partially) closed } \\
\hline & $\begin{array}{l}\text { Comparison } \\
\text { students/teachers }\end{array}$ & $\begin{array}{l}\text { Comparison } \\
\text { teachers/teachers }\end{array}$ & $\begin{array}{l}\text { Comparison teachers/ } \\
\text { population }\end{array}$ & $\begin{array}{l}\text { Comparison } \\
\text { students/teachers }\end{array}$ & $\begin{array}{l}\text { Comparison } \\
\text { teachers/teachers }\end{array}$ & $\begin{array}{l}\text { Comparison teachers/ } \\
\text { population }\end{array}$ \\
\hline $\begin{array}{l}\text { low } \\
\text { Case peak } 0-10 \\
\text { Death peak }<1\end{array}$ & $\begin{array}{l}\text { Attack rates: } \\
\text { Similar, no RR } \\
\text { calculable (1 study) }\end{array}$ & No studies & No studies & $\begin{array}{l}\text { Attack rates: } \\
\text { Similar (2 studies) }\end{array}$ & No studies & No studies \\
\hline $\begin{array}{l}\text { Medium } \\
\text { Case peak } \\
10-150 \\
\text { Death peak } \\
0.5-5\end{array}$ & $\begin{array}{l}\text { Attack rate: } \\
\text { Higher in teachers } \\
\text { (RR 1.6-4.4, } 3 \\
\text { studies) } \\
\text { Lower in teachers } \\
\text { (RR n.c., } 2 \text { studies) } \\
\text { Same (1 study) }\end{array}$ & No studies & No studies & $\begin{array}{l}\text { Infection risk: } \\
\text { Lower in teachers } \\
\text { (RR=0.3, } 1 \text { study) }\end{array}$ & No studies & No studies \\
\hline $\begin{array}{l}\text { High } \\
\text { Case peak } \\
\text { 90-1000 } \\
\text { Death peak } \\
\text { 5-20 }\end{array}$ & $\begin{array}{l}\text { Attack rate: } \\
\text { Higher in teachers } \\
\text { (RR } 1.21 \text { study) } \\
\text { Lower in teachers ( } \\
\text { NR, } 1 \text { study) }\end{array}$ & No studies & $\begin{array}{l}\text { Infection risk: } \\
\text { After school opening } \\
\text { higher ( } 1.42,1 \text { study) } \\
\text { Hospitalisation: } \\
\text { After school opening } \\
\text { similar ( } 0.97,1 \text { study) }\end{array}$ & No studies & $\begin{array}{l}\text { Infection risk: } \\
\text { Same to higher } \\
\text { in teachers in } \\
\text { presence compared } \\
\text { with distance (1.1.- } \\
2.0,2 \text { studies) }\end{array}$ & $\begin{array}{l}\text { Infection risk: } \\
\text { Before school opening } \\
\text { lower (RR } 0.5,1 \text { study) } \\
\text { Hospitalisation: } \\
\text { Before school opening } \\
\text { lower (RR } 0.5,1 \text { study) }\end{array}$ \\
\hline
\end{tabular}

re-opening compared with the general population, while hospitalisation risk was not increased $(\mathrm{RR}=0.97)$ concordantly. ${ }^{41}$ Thus, continuous presence of teaching staff in schools compared with intervals of or teachers in distance learning increases the risk of infection and also hospitalisation

This highlights the importance of transmission control measures such as contact tracing and fast quarantine orders. On detection of a single or few infections in schools, quarantine and testing strategies can help to prevent larger outbreaks. ${ }^{46}$ During large outbreaks transmission directions are less defined and attack rates are much higher. ${ }^{32}$

However, the dependence on local arrangements and testing strategies of the evidence presented is critical. For example, if only symptomatic cases are tested or only reported cases are evaluated, this can lead to high numbers of unreported asymptomatically infected or untested infected people. This distorts the comparison between teachers and pupils, as children experience a mild clinical course and fewer symptoms hence increasing the chance of being untested or not reported.

Similarly, seroprevalence studies reveal a heterogeneous picture with low evidence of infection incidence in the example of schools in Saxony, Germany during a data collection period with medium infection dynamics. However, the formation of antibodies is dependent on the intensity of the infection and immune response and can thus be underestimated, especially for children. Besides, it is difficult to reconstruct whether all detected infections occurred in the school environment.

\section{Limitation of the review}

There are limitations to this review. First, we did not conduct quantitative meta-analysis since the heterogeneity among included studies make them less comparable and hence meta-analysis was not right choice in this situation. Second, the included studies did not explicitly mentioned whether they tested only symptomatic or reported cases or both symptomatic and asymptomatic cases. Testing mainly symptomatic cases might skew results towards higher infection risks in school staff as adults typically have a higher proportion symptomatic infections. ${ }^{47}$ Third, we were not able to capture the endemicity and virulence of recent SARS-CoV-2 variant that is, alpha, beta and delta variant, as data gathered here refers to time periods in which these were not yet identified. Fourth, we exclude preprints or reports published only on homepages or institutional websites.

\section{CONCLUSION}

Despite of heterogeneity in the included studies, two conclusions can be drawn from this review. First, documenting local infection dynamics and implemented NPIs during data collection periods is crucial to understanding transmission dynamics in schools. Not all studies report these consistently. During periods of low incidence in the local population and schools with NPIs in place the risk to school staff is not necessarily higher than that of the general population and not comparable to the risk related to other high-risk professions such as healthcare staff. Studies reporting periods of high incidence are scarce but do show higher risk to school staff in these situations during periods where schools are not closed or NPIs are only partly in place. This may be due to the higher number and proximity of daily contacts in open schools compared with a general population under NPI public health measures.

Second, implementing screening and testing in schools is essential. In most of the included studies children seem less susceptible to SARS-CoV-2 infection. Students are less likely to transmit the virus to their peers or to teachers in the school setting. A large meta-analysis of prevalence studies ${ }^{3}$ and school outbreak studies ${ }^{48}$ 
supports this finding. However, these findings are biased by test strategies. If only symptomatic persons are tested and children show less symptoms, the number of positive cases in children is underestimated. Mass screenings of asymptomatic populations decrease the transmission of SARS-CoV-2. ${ }^{49}$ Mass testing after index cases and frequent testing of asymptomatic students and staff was shown to reduce transmission in schools, although not specifically the infection risk of staff. ${ }^{50}$ Mass testing and serial contact tracing and testing coupled with isolation and physical distancing can reduce the transmission SARS-CoV-2 in schools. $^{5152}$

\section{IMPLICATIONS}

In Germany, schools were reopened in February 2021 despite rising population incidences (predominantly due to increased endemicity of the variant B1.1.7, now accounting for over $70 \%$ of cases in Germany). ${ }^{53}$ A rise in cases among school-aged children is already reported by the Robert Koch Institute and the national average incidence exceeds 100 cases/100 000/7 days. ${ }^{53}$ Applying the conclusions to this scenario, we expect an increasing risk to school staff and students as social contacts in open schools will outnumber out-of-school contacts in a high community NPI and infection environment. Whereas the political discourse focuses primarily on the contribution of school cases to the overall infection dynamics, the reverse dependence of the infection risks in schools on community incidences and the associated health risk to staff and students is less discussed. Presumably, the school population is misleadingly thought of as young students (only) and thus considered to be less at risk of adverse outcomes. As we have demonstrated, the staff population has to be somewhat separated from the student population in terms of infection and transmission risks. Consequently, the risk to teachers and household contacts of students and staff should be considered more prominently in the balancing political decision around school openings and closures.

With that in mind, we recommend that legislators implement well-designed mass testing and serial contact tracing and testing strategies, also including asymptomatic individuals, to minimise the risk of school outbreaks during high infection dynamics

Acknowledgements We would like to thank Vanessa Melhorn for administrative help and Noah Hill for research assistant support.

Contributors BL had the idea for the review and initiated the work. SJK and AJ performed the search, screening, study selection and data extraction. SJK and AJ wrote the first draft of the manuscript. BL and TH contributed in writing. All authors critically revised and discussed the manuscript and approved submission of the final version. SJK and AJ contributed equally to this paper and shared the first authorship. BL and SJK act as a guarantor.

Funding This work was supported by public sources, namely the Standing Conference of the Ministers of Education and Cultural Affairs of the Federal States in the Federal Republic of Germany and by the European Union's Horizon 2020 research and innovation programme (grant number 101003480).

Disclaimer The study sponsors do not have any role in study design, in collection, analysis and interpretation of data, and in the decision to submit paper for publication.
Competing interests None declared.

Patient consent for publication Not applicable.

Provenance and peer review Not commissioned; externally peer reviewed.

Data availability statement Data sharing not applicable as no datasets generated and/or analysed for this study. No data are available. Not Applicable. In this systematic review no datasets were generated and analysed.

Supplemental material This content has been supplied by the author(s). It has not been vetted by BMJ Publishing Group Limited (BMJ) and may not have been peer-reviewed. Any opinions or recommendations discussed are solely those of the author(s) and are not endorsed by BMJ. BMJ disclaims all liability and responsibility arising from any reliance placed on the content. Where the content includes any translated material, BMJ does not warrant the accuracy and reliability of the translations (including but not limited to local regulations, clinical guidelines, terminology, drug names and drug dosages), and is not responsible for any error and/or omissions arising from translation and adaptation or otherwise.

Open access This is an open access article distributed in accordance with the Creative Commons Attribution Non Commercial (CC BY-NC 4.0) license, which permits others to distribute, remix, adapt, build upon this work non-commercially, and license their derivative works on different terms, provided the original work is properly cited, appropriate credit is given, any changes made indicated, and the use is non-commercial. See: http://creativecommons.org/licenses/by-nc/4.0/.

\section{ORCID iDs}

Sudip Jung Karki http://orcid.org/0000-0002-9643-9987

Torben Heinsohn http://orcid.org/0000-0002-1175-2633

\section{REFERENCES}

1 Wang M, Liao Z. SARS-CoV-2 and COVID-19: how much do we know? Acta Virol 2020;64:288-96.

2 Brodin P. Immune determinants of COVID-19 disease presentation and severity. Nat Med 2021;27:28-33.

3 Viner RM, Mytton OT, Bonell C, et al. Susceptibility to SARSCoV-2 infection among children and adolescents compared with adults: a systematic review and meta-analysis. JAMA Pediatr 2021;175:143-56.

4 Leung $C$. The younger the milder clinical course of COVID-19: even in newborns? Pediatr Allergy Immunol 2021;32:358-62.

5 Leung C. Clinical characteristics of COVID-19 in children: are they similar to those of SARS? Pediatr Pulmonol 2020;55:1592-7.

6 Patel NA. Pediatric COVID-19: systematic review of the literature. Am J Otolaryngol 2020;41:102573.

7 Mania A, Mazur-Melewska K, Lubarski K, et al. Wide spectrum of clinical picture of COVID-19 in children - From mild to severe disease. J Infect Public Health 2021;14:374-379.

8 Ludvigsson JF. Case report and systematic review suggest that children may experience similar long-term effects to adults after clinical COVID-19. Acta Paediatr 2021;110:914-21.

9 Viner RM, Russell SJ, Croker H, et al. School closure and management practices during coronavirus outbreaks including COVID-19: a rapid systematic review. Lancet Child Adolesc Health 2020;4:397-404.

10 Anderson RM, Heesterbeek H, Klinkenberg D, et al. How will countrybased mitigation measures influence the course of the COVID-19 epidemic? Lancet 2020;395:931-4.

11 Bo Y, Guo C, Lin C, et al. Effectiveness of non-pharmaceutical interventions on COVID-19 transmission in 190 countries from 23 January to 13 April 2020. Int J Infect Dis 2021;102:247-53.

12 ECDC. COVID-19 in children and the role of school settings in COVID-19 transmission, 2020.

13 Goldstein E, Lipsitch M, Cevik M. On the effect of age on the transmission of SARS-CoV-2 in households, schools and the community. medRxiv 2020. doi:10.1101/2020.07.19.20157362. [Epub ahead of print: 28 Jul 2020].

$14 \mathrm{Li} \mathrm{Y,} \mathrm{Campbell} \mathrm{H,} \mathrm{Kulkarni} \mathrm{D,} \mathrm{et} \mathrm{al.} \mathrm{The} \mathrm{temporal} \mathrm{association} \mathrm{of}$ introducing and lifting non-pharmaceutical interventions with the time-varying reproduction number $(R)$ of SARS-CoV-2: a modelling study across 131 countries. Lancet Infect Dis 2021;21:193-202.

15 Brauner JM, Mindermann S, Sharma M, et al. Inferring the effectiveness of government interventions against COVID-19. Science 2021;371. doi:10.1126/science.abd9338. [Epub ahead of print: 19 Feb 2021].

16 Armitage R, Nellums LB. Considering inequalities in the school closure response to COVID-19. Lancet Glob Health 2020;8:e644. 
17 Dunn CG, Kenney E, Fleischhacker SE, et al. Feeding low-income children during the Covid-19 pandemic. N Engl J Med 2020;382:e40.

18 Levinson M, Cevik M, Lipsitch M. Reopening primary schools during the pandemic. N Engl J Med 2020;383:981-5.

19 Van Lancker W, Parolin Z. COVID-19, school closures, and child poverty: a social crisis in the making. Lancet Public Health 2020;5:e243-4.

20 Yoshikawa H, Wuermli AJ, Britto PR, et al. Effects of the global coronavirus Disease-2019 pandemic on early childhood development: short- and long-term risks and mitigating program and policy actions. J Pediatr 2020;223:188-93.

21 Moher D, Liberati A, Tetzlaff J, et al. Preferred reporting items for systematic reviews and meta-analyses: the PRISMA statement. PLoS Med 2009;6:e1000097.

22 Hartling L, Bond K, Harvey K. AHRQ methods for effective health care. developing and testing a tool for the classification of study designs in systematic reviews of interventions and exposures. Rockville (MD): Agency for Healthcare Research and Quality (US), 2010.

23 Viswanathan M, Ansari MT, Berkman ND. AHRQ methods for effective health care assessing the risk of bias of individual studies in systematic reviews of health care interventions. methods guide for effectiveness and comparative effectiveness reviews. Rockville (MD): Agency for Healthcare Research and Quality (US), 2008.

24 Zeng X, Zhang Y, Kwong JSW, et al. The methodological quality assessment tools for preclinical and clinical studies, systematic review and meta-analysis, and clinical practice guideline: a systematic review. J Evid Based Med 2015;8:2-10.

25 Armann JP, Unrath M, Kirsten C. SARS-CoV-2 IgG antibodies in adolescent students and their teachers in Saxony, Germany (Schoo/CoviDD19): persistent low seroprevalence and transmission rates between may and October 2020, 2020.

26 Brown NE, Bryant-Genevier J, Bandy U, et al. Antibody responses after classroom exposure to teacher with coronavirus disease, March 2020. Emerg Infect Dis 2020;26:2263-5.

27 Danis K, Epaulard O, Bénet T, et al. Cluster of coronavirus disease 2019 (COVID-19) in the French Alps, February 2020. Clin Infect Dis 2020;71:825-32.

28 Fontanet A, Tondeur L, Madec Y, et al. Cluster of COVID-19 in northern France: a retrospective closed cohort study. SSRN J 2020.

29 Hernandez A, Muñoz P, Rojas JC, et al. Epidemiological chronicle of the first recovered coronavirus disease patient from Panama: evidence of early cluster transmission in a high school of Panama City. Front Public Health 2020;8:553730.

30 Macartney K, Quinn HE, Pillsbury AJ, et al. Transmission of SARSCoV-2 in Australian educational settings: a prospective cohort study. Lancet Child Adolesc Health 2020;4:807-16.

31 Public Health Agency S. Presence of COVID-19 in different occupational group. Sweden: Public Health Agency, 2020

32 Stein-Zamir C, Abramson N, Shoob H, et al. A large COVID-19 outbreak in a high school 10 days after schools' reopening, Israel, may 2020. Euro Surveill 2020;25.

33 Vlachos J, Hertegård E, Svaleryd H. School closures and SARSCoV-2. Evidence from Sweden's partial school closure. medRxiv 2020.

34 Yung CF, Kam K-Q, Nadua KD, et al. Novel coronavirus 2019 transmission risk in educational settings. Clin Infect Dis 2021;72:1055-8.

35 (NCIRS) NCfIRaS. COVID-19 in schools and early childhood education and care services - the Term 2 experience in NSW.
Australia: National Centre for Immunisation Research and Surveillance (NCIRS), 2020

36 Ismail SA, Saliba V, Lopez Bernal J, et al. SARS-CoV-2 infection and transmission in educational settings: a prospective, cross-sectional analysis of infection clusters and outbreaks in England. Lancet Infect Dis 2021;21:344-53.

37 Lopez L, Nguyen T, Weber G. Seroprevalence of anti-SARSCoV-2 IgG antibodies in the staff of a public school system in the midwestern United States. medRxiv 2020.

38 (NCIRS) NCfIRaS. COVID-19 in schools and early childhood education and care services - the Term 3 experience in NSW. National Centre for Immunisation Research and Surveillance (NCIRS), 2020.

39 Falk A, Benda A, Falk P, et al. COVID-19 Cases and Transmission in 17 K-12 Schools - Wood County, Wisconsin, August 31-November 29, 2020. MMWR Morb Mortal Wkly Rep 2021;70:136-40.

40 Larosa E, Djuric O, Cassinadri M, et al. Secondary transmission of COVID-19 in preschool and school settings in northern Italy after their reopening in September 2020: a population-based study. Euro Surveill 2020;25.

41 Lynda F, Ciara G, David C. Risk of hospitalisation with COVID-19 among teachers compared to healthcare workers and other workingage adults. A nationwide case-control study. medRxiv 2021.

42 Heavey L, Casey G, Kelly C, et al. No evidence of secondary transmission of COVID-19 from children attending school in Ireland, 2020. Euro Surveill 2020;25.

43 Max Roser HR, Ortiz-Ospina E, Hasell J. Coronavirus pandemic (COVID-19), 2021. Available: https://ourworldindata.org/coronavirus

44 Starr M. Back to school: safe for children with underlying medical conditions. Aust J Gen Pract 2020;49. doi:10.31128/AJGPCOVID-21. [Epub ahead of print: 19 May 2020].

$45 \mathrm{Li}$ X, Xu W, Dozier M, et al. The role of children in transmission of SARS-CoV-2: a rapid review. J Glob Health 2020;10:011101.

46 Wells CR, Townsend JP, Pandey A, et al. Optimal COVID-19 quarantine and testing strategies. Nat Commun 2021;12:356

47 Davies NG, Klepac P, Liu Y, et al. Age-Dependent effects in the transmission and control of COVID-19 epidemics. Nat Med 2020;26:1205-11.

48 Otte Im Kampe E, Lehfeld A-S, Buda S, et al. Surveillance of COVID-19 school outbreaks, Germany, March to August 2020. Euro Surveill 2020;25.

49 Larremore DB, Wilder B, Lester E, et al. Test sensitivity is secondary to frequency and turnaround time for COVID-19 screening. Sci Adv 2021;7:eabd5393.

50 Rafiei Y, Mello MM. The missing piece - SARS-CoV-2 testing and school reopening. N Engl J Med Overseas Ed 2020;383:e126.

51 Leng T, Hill EM, Thompson RN. Assessing the impact of secondary school reopening strategies on within-school COVID-19 transmission and absences: a modelling study. medRxiv 2021

52 Kucharski AJ, Klepac P, Conlan AJK, et al. Effectiveness of isolation, testing, contact tracing, and physical distancing on reducing transmission of SARS-CoV-2 in different settings: a mathematical modelling study. Lancet Infect Dis 2020;20:1151-60.

53 RKI. Täglicher Lagebericht des RKI zur Coronavirus-Krankheit-2019 (COVID-19) 24.03.2021 - Aktualisierter stand fur deutschland. Germany: Robert Koch Institute, 2021. Available: https:// www.rki.de/DE/Content/InfAZ/N/Neuartiges_Coronavirus/ Situationsberichte/Maerz_2021/2021-03-24-de.pdf?_blob= publicationFile $\% 27$ 